Cite this: RSC Adv., 2017, 7, 13707

Received 9th November 2016 Accepted 14th February 2017

DOI: 10.1039/c6ra26541c

rsc.li/rsc-advances

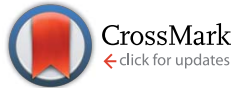

\section{Preparation and performance of composite films based on 2-(2-aminoethoxy) ethyl chitosan and cellulose}

\begin{abstract}
Xiaofei Liu, ${ }^{\text {*abc }}$ Zongbao Liu, ${ }^{\text {abc }}$ Li Wang, ${ }^{\text {abc }}$ Shengsheng Zhang ${ }^{\text {abc }}$ and Hai Zhang ${ }^{\text {abc }}$
In this study, antioxidant active films were prepared from 2-(2-aminoethoxy) ethyl chitosan (AECs, a novel chitosan derivative) and cellulose under an environmentally friendly process using ionic liquids (ILs). AEC/ cellulose composite films were prepared by efficiently blending AECs into cellulose $\mathrm{N}$-methylmorpholine $\mathrm{N}$-oxide $(\mathrm{NMMO}) / \mathrm{H}_{2} \mathrm{O}$ solution, followed by shaping in a mold. The microstructure, physical, mechanical and antioxidant properties of the composite films were measured. The resulting composite films exhibited good physical properties, favorable mechanical properties and a high free radical scavenging activity against 2,2-diphenyl-1-picrylhydrazyl (DPPH) in methanol. Furthermore, a loading of AECs at 5\% into cellulose resulted in significant improvement in antioxidant activity $(86.5 \% \pm 2.7 \%$ ), while a slight decrease in the tensile strength $(2.9 \% \pm 0.2 \%)$ was noted. This result indicated that the oxidation resistance can be greatly improved by incorporation of AECs without significantly affecting the mechanical properties. The bioactive composite film is expected to be a promising material for potential applications in food packaging.
\end{abstract}

\section{Introduction}

In recent years, there has been a growing interest in the development of food packaging based on natural macromolecules that are environmentally friendly, biodegradable and renewable because the packaging can not only reduce plastic waste but also enhance food quality by preserving moisture, water vapor permeability and antioxidant activity., Cellulose, the most abundant biopolymer consisting of D-glucopyranose units connected by $\beta$-1,4-glycosidic bonds, is capable of forming a structural matrix with a sufficient cohesiveness due to its superior ability to form films and mechanical behavior., The excellent biological properties of cellulose show great promise for its application in food packaging. ${ }^{5,6}$ New trends in cellulose have focused on the improvement of its functionality through incorporation of active compounds, such as antioxidant agents. ${ }^{7-9}$

Chitosan (the cationic (1-4)-2-amino-2-deoxy- $\beta$-D-glucan) is a non-toxic and biodegradable polymer obtained from the deacetylation of chitin and has excellent biocompatibility, film forming ability and antioxidant activity. ${ }^{\mathbf{1 0 , 1 1}}$ In order to improve

${ }^{a}$ Department of Polymer Materials Science and Engineering, College of Materials Science and Engineering, Tianjin University, Tianjin, 300072, P. R. China. E-mail: liuxf315@aliyun.com

${ }^{b}$ Research Institute of Advanced Polymer, Tianjin University, Tianjin, 300072, P. R. China

'Tianjin Key Laboratory of Composite and Functional Materials, Tianjin University, Tianjin, 300072, P. R. China the solubility, physicochemical and biological properties of chitosan, much effort has been made to introduce hydrophilic groups by covalent attachment to reactive amino groups. ${ }^{\mathbf{1 2 - 1 4}}$ Various types of chitosan derivatives with good antioxidant activity have been investigated. ${ }^{15-17}$ Therefore, it is possible to prepare chitosan derivative/cellulose composite films, in which chitosan acts as an additive to improve the properties of cellulose and endows it good antioxidant ability. ${ }^{\mathbf{1 8 - 2 0}}$

Previously, the preparation of cellulose films was usually carried out through the viscose process, which was harmful to the environment. ${ }^{21-23}$ As a result, ionic liquids (ILs), novel green solvents and catalysts, were regarded as promising alternatives to green solvents to replace the organic solvents in cellulose film formation. ${ }^{24,25}$ It was reported that several promising solvent systems, such as $\mathrm{LiCl} / \mathrm{N}, \mathrm{N}$-dimethylacetamide (DMAc), dimethylformamide, and $N$-methylmorpholine $\mathrm{N}$-oxide (NMMO) $/ \mathrm{H}_{2} \mathrm{O}$, have been utilized to prepare chitosan/ cellulose blends. ${ }^{26,27}$ In particular, NMMO solution was technically feasible and has been widely applied in industrial production. ${ }^{28,29}$

The aim of this study was to develop a fully green approach for the preparation of bioactive films from renewable resources through the use of cellulose as the film matrix and the incorporation of various amounts of AECs, a novel chitosan derivative as an antioxidant agent. Extensive characterization of AEC/ cellulose composite films revealed unique properties of these films and how the additive AECs affected the microstructure, physical and mechanical properties and antioxidant activity. 


\section{Experimental}

\subsection{Chemicals and materials}

Chitosan (molecular weight $1.08 \times 10^{6}$, the degree of deacetylation was 0.85) was supplied by Qingdao Medicine Institute (Shandong, China) and degraded by $\gamma$-irradiation to various molecular weight samples. The molecular weight for the original chitosan was $1.9 \times 10^{5} \mathrm{~g} \mathrm{~mol}^{-1}$. Cellulose pulp (DP = 750) was provided by Tianjin Rayon Factory (Tianjin, China), which was dried at $80{ }^{\circ} \mathrm{C}$ for $24 \mathrm{~h}$ before use. $\mathrm{N}$-Methylmorpholine-Noxide (NMMO) aqueous solution (50 wt\%) was purchased from BASF, Germany. 2,2-Diphenyl-1-picrylhydrazyl (DPPH) was purchased from Sigma-Aldrich (St. Louis, MO). Other reagents were of analytical grade and provided by Jiangtian Chemical Technology (Tianjin, China).

\subsection{Film preparation}

2.2.1 Synthesis of AECs. Fig. 1 shows the synthetic process of AECs. Chitosan was suspended in sodium hydroxide $(\mathrm{NaOH}$, $42 \mathrm{wt} \%$ ) solution and then reacted with 2-chloroethanol at $25{ }^{\circ} \mathrm{C}$ for $12 \mathrm{~h}$. After the filtration, hydroxyethyl chitosan (HECs) was dried at $60{ }^{\circ} \mathrm{C}$ under vacuum. Then, HECs $(5 \mathrm{~g})$ was dissolved in $\mathrm{NaOH}(42 \mathrm{wt} \%)$ solution and reacted with 2-chloroethylamine hydrochloride at $80^{\circ} \mathrm{C}$ for $12 \mathrm{~h}$. After the reaction, the $\mathrm{pH}$ of the solution was adjusted to 7.0 with hydrochloric acid. The crude product was dialyzed, lyophilized, and dried. The $\mathrm{NH}_{2} \%$ of AECs was determined by potentiometric titration (PT).

2.2.2 Preparation of AEC/cellulose co-solution. An AEC/ cellulose co-solution was prepared as follows: $10 \mathrm{~g}$ cellulose was pulverized and dipped in $200 \mathrm{~mL} \mathrm{NMMO} / \mathrm{H}_{2} \mathrm{O}(50 \mathrm{wt} \%)$, heated to $110{ }^{\circ} \mathrm{C}$ and stirred in a vacuum until the content of $\mathrm{H}_{2} \mathrm{O}$ reduced to $13.3 \mathrm{wt} \%\left(\mathrm{wt} \%=\mathrm{H}_{2} \mathrm{O} /\left(\mathrm{NMMO} / \mathrm{H}_{2} \mathrm{O}\right)\right) .{ }^{30}$ Then, the cellulose was filtered and completely dissolved in NMMO/ $\mathrm{H}_{2} \mathrm{O}$ under stirring. AECs powder $(5 \mathrm{~g})$ was dissolved in $10 \mathrm{~mL}$ of
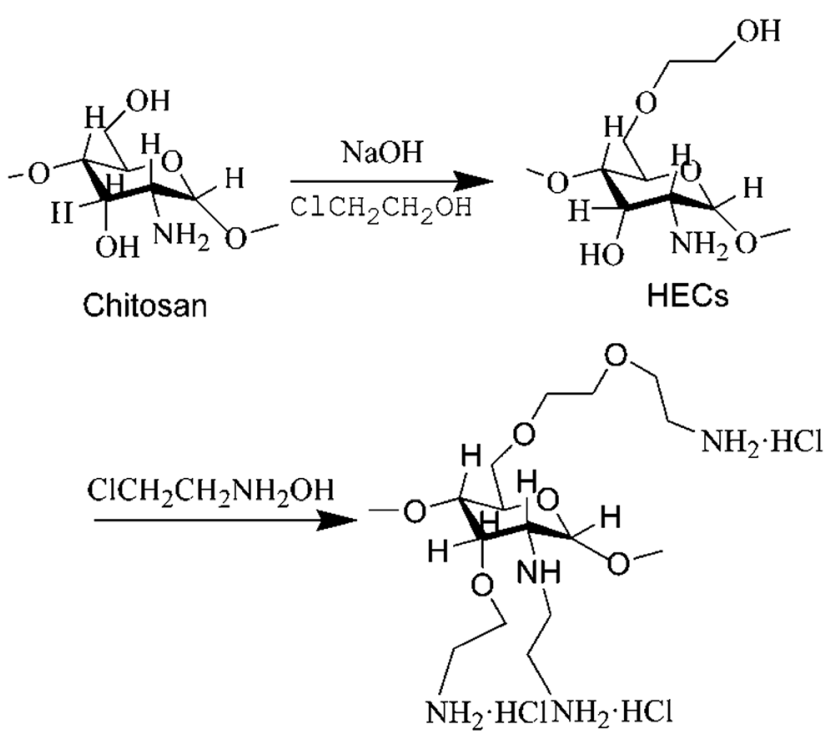

AECs sodium hydroxide solution (5 wt\%). Then, the mixture was added into a cellulose $\mathrm{NMMO} / \mathrm{H}_{2} \mathrm{O}$ solution under vigorous stirring to obtain an AEC/cellulose co-solution.

2.2.3 Preparation of AEC/cellulose composite films. Through co-solution of AECs and cellulose in the $\mathrm{NMMO} / \mathrm{H}_{2} \mathrm{O}$ system, AEC/cellulose composite films were shaped in a mold at a stable temperature of $90{ }^{\circ} \mathrm{C}$, and deionized water was used as a coagulation bath. The resultant films were washed three times to ensure complete coagulation and removal of NMMO. The thickness of the films was controlled to about $50 \mu \mathrm{m}$. The cellulose film was obtained using the same method.

\subsection{Film microstructure}

2.3.1 Fourier transform infrared spectroscopy (FTIR) analysis. FTIR spectra of AECs and AEC/cellulose composite films were obtained with a Nicolet 560 E.S.P. spectrometer. The samples were scanned from 400 to $4000 \mathrm{~cm}^{-1}$ with a resolution of $1 \mathrm{~cm}^{-1}$.

2.3.2 Wide angle X-ray scattering (WAXS). WAXS experiments were performed for the films using a D/max-2500 X-ray diffractometer. The X-ray source was Ni-filtered $\mathrm{CuK} \alpha$ radiation $(25 \mathrm{kV}, 10 \mathrm{~mA})$. Samples were scanned at a range of $2 \theta$ from $5^{\circ}$ to $40^{\circ}$ at a scan rate of $4^{\circ} \mathrm{min}^{-1}$.

2.3.3 Scanning electron microscopy (SEM). SEM observations were made on the films. Films were coated with a small amount of gold and examined with a Philips SL-30 SEM.

\subsection{Physical properties}

2.4.1 Film thickness measurement. Thicknesses of the films were analyzed on a digital micrometer (RCBS Electronic Digital Micrometer). The thickness was tested at 12 randomly selected points of the same film, and then an average value was calculated.

2.4.2 Equilibrium moisture content. The water content of film samples was determined by measuring the weight loss of films. Films samples were conditioned under standard conditions $\left(25{ }^{\circ} \mathrm{C}, 70 \%\right.$ relative humidity) for $24 \mathrm{~h}$ before weighing (wet sample weight) and dried in triplicate at $105{ }^{\circ} \mathrm{C}$ for $24 \mathrm{~h}$ more in a vacuum oven until reaching a constant weight (dry sample weight). The equilibrium moisture content (\%) was calculated from the following expression:

Equilibrium moisture content $(\%)=$

$$
\left(\frac{\text { wet sample weight }}{\text { dry sample weight }}-1\right) \times 100
$$

2.4.3 Film solubility in water. The water solubility of film samples was determined by immersing dried, weighed test samples (initial dry weight) into test beakers with distilled water for $24 \mathrm{~h}$ at room temperature. Then, each sample was dried at $105{ }^{\circ} \mathrm{C}$ for $24 \mathrm{~h}$ to determine the weight of the final dry matter. Every experiment was performed 5 times. The percentage of film solubility was calculated based on the following equation:

$$
\text { Solubility }(\%)=\left(1-\frac{\text { final dry weight }}{\text { initial dry weight }}\right) \times 100
$$

Fig. 1 Synthesis of AECs. 
2.4.4 Water vapor permeability (WVP). The WVP of films was determined by a modified ASTM method as described in a previous study at a constant temperature of $20{ }^{\circ} \mathrm{C} .{ }^{31}$ The film samples, cut into disks, were sealed to cups with an average diameter of $2 \mathrm{~cm}$ and a depth of $4.5 \mathrm{~cm}$. After steady-state conditions were reached (about $2 \mathrm{~h}$ ), the cups were weighed every $2 \mathrm{~h}$ over a period of $24 \mathrm{~h}$. Tests were conducted in duplicate for each sample, and the slope, obtained from regression analysis of weight loss data as a function of time, was used to calculate WVP, according to ATSM. ${ }^{32}$

\subsection{Mechanical properties}

Mechanical properties of film samples were determined using M350-20KN Testometric. The tensile strength and elongation of the films were measured. The tests were carried out in accordance with the standard ISO 6239-1986 (E), and the stretching rate was $5 \mathrm{~mm} \mathrm{~min}^{-1}$. Surface tension of the films was measured by a dynamic contact angle measurement instrument and Tensionmeter, DataPhysics DCAT 21.

\subsection{Antioxidant activity}

The antioxidant activity of films was measured using the 2,2diphenyl-1-picrylhydrazyl (DPPH) radical method according to a procedure previously described. ${ }^{33,34}$ The films were cut and dipped in the methanol solution of DPPH $\left(0.030 \mathrm{~g} \mathrm{~mL}^{-1}\right)$ under magnetic stirring for $12 \mathrm{~h}$ at $25^{\circ} \mathrm{C}$. The decrease in absorbance was monitored by UV-Vis absorption spectrometry at $515 \mathrm{~nm}$. The experiments were repeated 5 times for the evaluation of each antioxidant activity. DPPH radical scavenging activity was calculated as inhibition percentage as follows:

Free radical scavenging activity $(\%)=\left(1-\frac{\mathrm{Abs}_{\text {sample }}}{\mathrm{Abs}_{\text {control }}}\right) \times 100$

\subsection{Statistical analysis}

All values reported were from replicate determinations with basic mathematical calculations and analysis. A statistical analysis of data was obtained through a one-way analysis of variance. Homogeneous sample groups were performed by Fisher's protected least-significant difference (LSD) test and the significance level used was 0.05 .

\section{Results and discussion}

\subsection{Synthesis and solubility of AECs}

The FTIR spectra of HECs and AECs are displayed in Fig. 2. In the FTIR spectrum of HECs, the main characteristic peaks at $1058 \mathrm{~cm}^{-1}$ were assigned to the stretching vibration of the $\mathrm{C}-\mathrm{O}$ group, and $1313 \mathrm{~cm}^{-1}$ was assigned to the $\mathrm{O}-\mathrm{H}$ bending vibration. The absorptions at $1650 \mathrm{~cm}^{-1}$ and $892 \mathrm{~cm}^{-1}$ showed evidence for the presence of $\mathrm{N}-\mathrm{H}$ groups. The spectrum of AECs, on the other hand, exhibited an absorption of a $-\mathrm{NH}_{2}$ bending vibration at $1618 \mathrm{~cm}^{-1}$ and the peak for the $-\mathrm{CH}_{2}-\mathrm{N}-$ bending

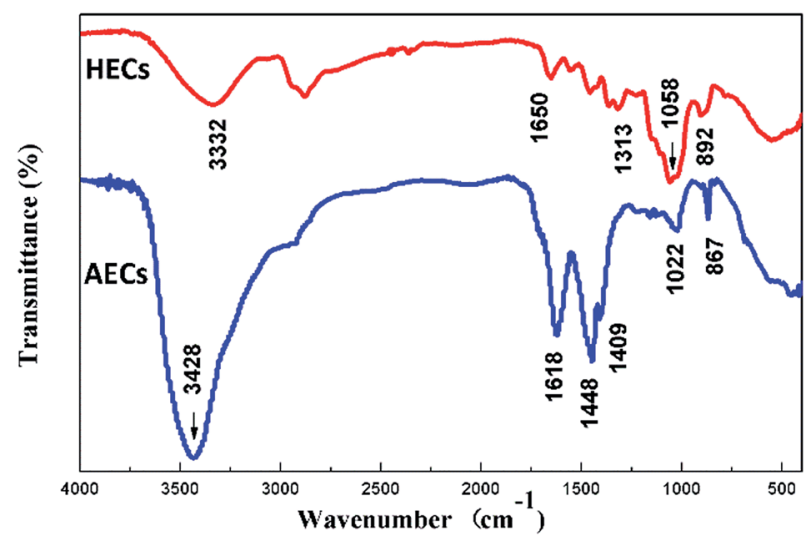

Fig. 2 FTIR spectrum of HECS and AECs.

vibration at $1448 \mathrm{~cm}^{-1}$. In addition, the absence of the $-\mathrm{OH}$ absorption at $1058 \mathrm{~cm}^{-1}$ and the absorption of the secondary amino group at $1022 \mathrm{~cm}^{-1}$ indicated that the amination reaction occurred at both hydroxyl and amino groups. ${ }^{35}$ Due to the introduction of a number of $-\mathrm{NH}_{2}$ groups, the absorption of the $-\mathrm{NH}_{2}$ stretching vibration at $3428 \mathrm{~cm}^{-1}$ was enhanced.

The structure of AECs was further explored by ${ }^{13} \mathrm{C}-\mathrm{NMR}$ (Fig. 3). The ${ }^{13} \mathrm{C}-\mathrm{NMR}$ spectrum was recorded on a MercuryVx300 spectrometer in $\mathrm{D}_{2} \mathrm{O} / \mathrm{CF}_{3} \mathrm{COOD} 95: 5 \mathrm{v} / \mathrm{v}$. The peaks observed at $97.6 \mathrm{ppm}, 56.7 \mathrm{ppm}, 70.1 \mathrm{ppm}, 76.7 \mathrm{ppm}, 74.0 \mathrm{ppm}$, $60.1 \mathrm{ppm}$ corresponded to the pyranoid ring $(\mathrm{C}-1,2,3,4,5,6)$, respectively. The peak at $83.9 \mathrm{ppm}$ was ascribed to $-\mathrm{CH}_{2} \mathrm{NH}_{2}$, another peak at $48.2 \mathrm{ppm}$ was attributed to $-\mathrm{CH}_{2}-\mathrm{O}-$, and the peak at $22.2 \mathrm{ppm}$ was assigned to $-\mathrm{CH}_{3} \cdot{ }^{36}$ FTIR and ${ }^{13} \mathrm{C}$ NMR confirmed that the quaternary amino salt group was introduced onto chitosan, and AECs were successfully synthesized.

The solubilities of AECs synthesized under various conditions in $\mathrm{NMMO} / \mathrm{H}_{2} \mathrm{O}$ are given in Table 1 . The results show that all samples obtained from the original chitosan could dissolve in aqueous $\mathrm{NMMO} / \mathrm{H}_{2} \mathrm{O}$ except the one in experiment no. 1 ; in particular, the solubility of AECs in $\mathrm{NMMO} / \mathrm{H}_{2} \mathrm{O}$ in experiment no. 5 reached $63.5 \mathrm{mg} \mathrm{mL}^{-1}$. Due to the hydration of the amino group in $\mathrm{NMMO} / \mathrm{H}_{2} \mathrm{O}$, AECs had good solubility, which benefited spinning and film formation. The incorporation of a polar group into the chitosan backbone offered excellent water solubility.

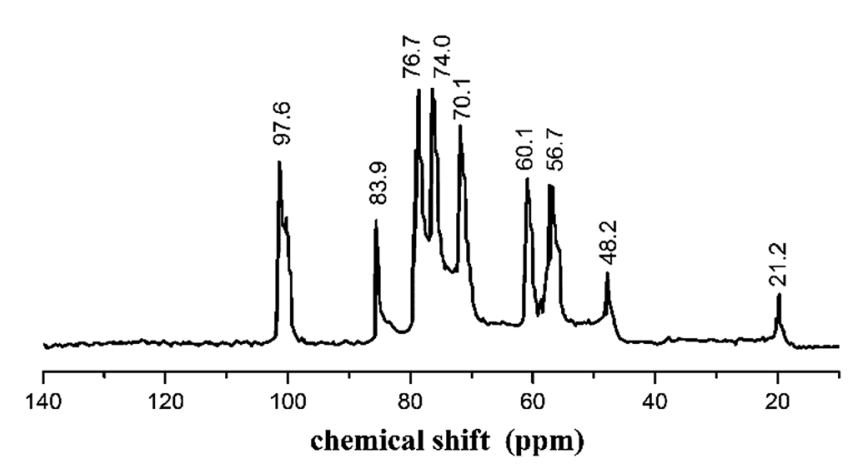

Fig. $3{ }^{13} \mathrm{C}-\mathrm{NMR}$ spectrum of AECs. 
Table 1 Solubility of AECs in $\mathrm{NMMO} / \mathrm{H}_{2} \mathrm{O}$

\begin{tabular}{lllllllll}
\hline Experiment no. & 1 & 2 & 3 & 4 & 5 & 6 & 7 & 8 \\
Time (h) & 6 & 12 & 24 & 6 & 12 & 24 & 6 & 12 \\
Temperature $\left({ }^{\circ} \mathrm{C}\right)$ & 50 & 70 & 80 & 70 & 80 & 50 & 80 & 50 \\
$\mathrm{NH}_{2} \%$ & 8.4 & 9.51 & 9.85 & 10.31 & 10.7 & 9.36 & 9.85 & 10.5 \\
Solubility $\left(\mathrm{mg} \mathrm{mL}^{-1}\right)$ & - & 12.3 & 40.8 & 14.6 & 63.5 & 35.7 & 53.1 & 10.2 \\
\hline
\end{tabular}

\subsection{Film microstructure}

The structure of the composite films was studied via FTIR spectroscopy (Fig. 4). In the spectrum of cellulose, the absorption band of the hydroxyl group was wide and strong ranging from $3310 \mathrm{~cm}^{-1}$ to $3520 \mathrm{~cm}^{-1}$, and the peak at $2895 \mathrm{~cm}^{-1}$ was assigned to the stretching vibration of $\mathrm{C}-\mathrm{H}$. The spectrum of AEC/cellulose composite films was very similar to that of AECs. The strong absorption band at $1618 \mathrm{~cm}^{-1}$ was the deformation vibration of $-\mathrm{NH}_{2}$, and the peaks appearing at $1448 \mathrm{~cm}^{-1}$ and $1409 \mathrm{~cm}^{-1}$ corresponded to the deformation vibration and wagging vibration of $-\mathrm{CH}_{2}$ in the $-\mathrm{CH}_{2}-\mathrm{N}-$, respectively. Compared with AECs, a slight motion at the high wavenumber of $-\mathrm{NH}_{2}$ was observed in the spectrum of AECs/cellulose composite films, indicating that an interaction between AECs and cellulose existed, proving the compatibility between AECs and cellulose.

X-ray scattering patterns of cellulose pulp, cellulose film and AEC/cellulose composite films were also studied as shown in Fig. 5. Cellulose pulp showed a diffraction pattern for cellulose I, while cellulose film generally showed a diffraction pattern for cellulose II at $2 \theta=12^{\circ}$ for $(101), 20^{\circ}$ for $(101)$, and $21.7^{\circ}$ for (002). ${ }^{37}$ Compared with the cellulose film, the height of the peak at $12^{\circ}$ for (101) in the diffraction patterns of AEC/cellulose

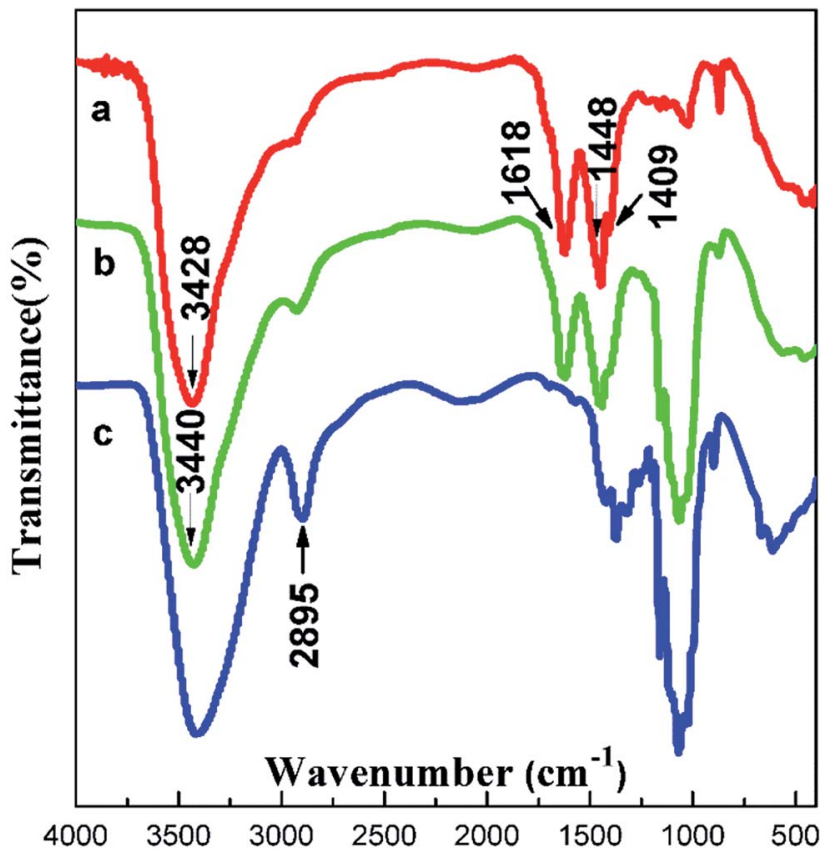

Fig. 4 FTIR spectra of (a) AECs, (b) AECs/cellulose composite films and (c) cellulose. composite films evidently declined with an increased content of AECs. This indicates that the interaction between AECs and cellulose broke the intermolecular hydrogen bonds between cellulose chains, which led to the weakness of the peak at $12^{\circ}$ for (101). ${ }^{38}$

SEM microphotographs of the surfaces of cellulose and composite films are shown in Fig. 6, respectively. Because the cellulose and composite films were separated out from the solution during the longitudinal deformation and soft coagulation, there were holes in the surface of all the films (Fig. 6). Unlike the cellulose film, there were fewer and smaller holes for composite films. The cellulose film displayed a zigzag section, while the section of composite film was smooth and homogeneous. We attributed this morphological difference to the additive AECs, which may have changed the crystal structure of the cellulose film.

\subsection{Physical properties}

Homogeneous, thin and flexible films were obtained from the AECs/cellulose blending. Thicknesses of films varied between $50.46 \pm 0.79$ and $52.39 \pm 3.25 \mu \mathrm{m}$, as shown in Table 2. As the amount of AECs in the films increased, the thicknesses of the films increased as well. This change in thickness may be caused by the compact difference between cellulose chains, groups of AECs and their interactions. When AECs was added to cellulose matrix, an interconnected bonding network could be formed by the hydrogen bonds.

The composite films with various amounts of AECs showed higher moisture content than cellulose films without AECs (Table 2), suggesting that AECs were more hydrophilic than

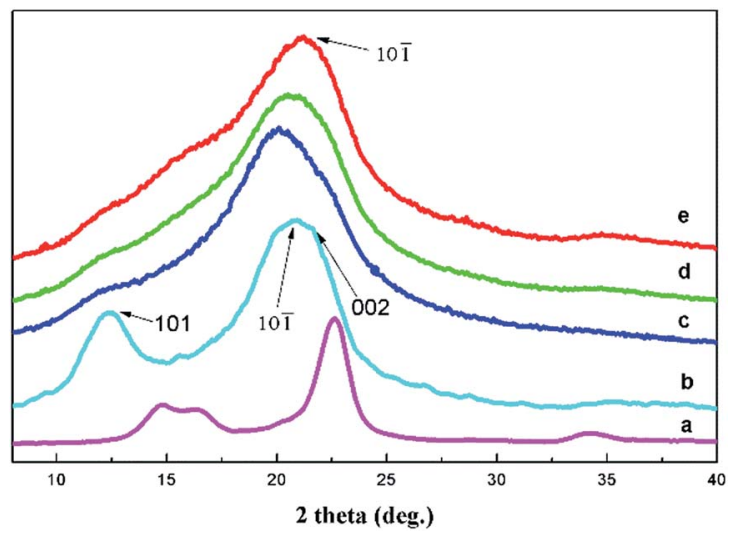

Fig. 5 X-ray diffraction patterns of the cellulose pulp (a), cellulose film (b) and the composite films with different contents of AECs: (c) $1 \%$, (d) $3 \%$ and (e) $5 \%$. 

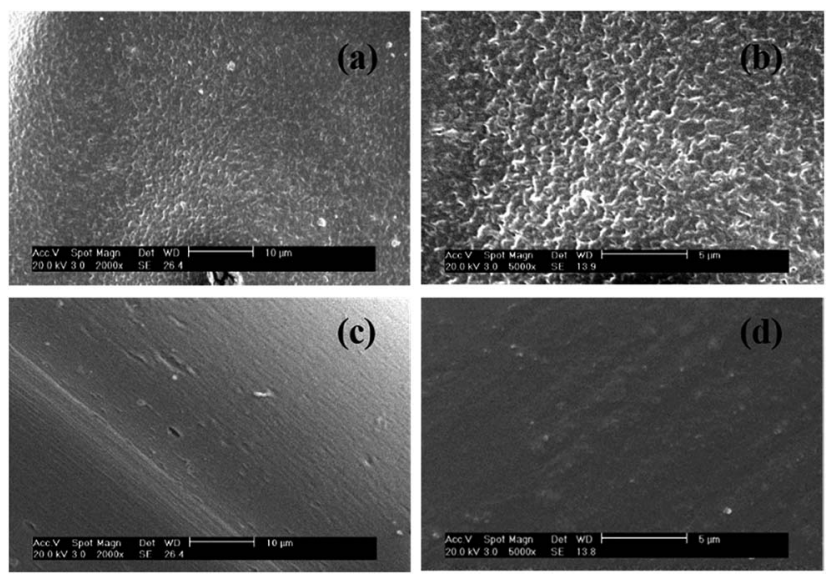

Fig. 6 SEM images of (a) cellulose film's section 2000x, (b) cellulose film's section 5000x, (c) composite film's section 2000x and (d) composite film's section $5000 \times$.

cellulose. Cellulose and composite films had low solubility values, and the incorporation of AECs into the cellulose matrix significantly increased the solubility in water (Table 2). Hydrogen bonds between the cellulose chains and the quaternary amino salt group of AECs were the driving forces for the water solubility. ${ }^{\mathbf{3 9}, 40}$ Accordingly, AEC/cellulose composite films are not desirable for preserving liquid or liquid-containing food.

Table 2 also shows the water vapor permeability (WVP) values of the cellulose and composite films. The WVP values of the composite films, after adding AECs, increased to 7.32-7.67 $\times 10^{-11} \mathrm{~g} \mathrm{~m}^{-1} \mathrm{~s}^{-1} \mathrm{~Pa}^{-1}$ due to the higher water affinity of AEC/ cellulose composite films. Since WVP is the contribution of diffusivity and solubility of the films through the matrix, ${ }^{41}$ composite films showed higher water vapor permeability than the cellulose film. Due to the greater number of hydrophilic groups of AECs and the presence of a greater amount of water molecules in the composite films, it is likely that the structural changes, induced by the addition of AECs, resulted in notable changes for the mass transfer rate of water molecules and greatly affected permeability values.

\subsection{Characterization of surface tension}

The effects of the content of AECs on the surface tension of cellulose and composite films are given in Fig. 7. The surface tension of the films decreased with an increasing content of AECs, which indicates that the moisture absorption of

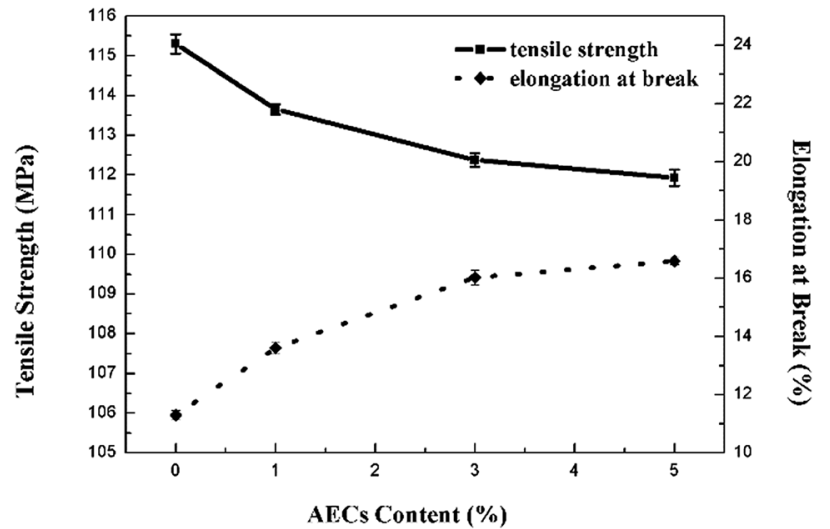

Fig. 7 Mechanical properties of the films with various contents of AECs.

composite films was better than that of the cellulose film due to the significant moisture performance of AECs. This result agreed well with DSC analysis, which showed that the enthalpy of water loss increased with increased content of AECs.

\subsection{Mechanical properties}

The tensile strength and elongation of cellulose and composite films in the dry state are shown in Fig. 8. The tensile strength of the films showed a continuous minor decrease with an increased content of AECs. Although the additive AECs may interfere with the orientation and crystallization of cellulose, the effect of small amounts of AECs was so weak that the performance of the films was not strongly influenced. Moreover, the films with AECs exhibited higher elongation, indicating that the addition of AECs could improve the flexibility of the composite films, which agreed well with the SEM microphotographs.

\subsection{Antioxidant activity}

The antioxidant activity of films was evaluated by means of the dissolution of the film in a controlled amount of distilled water. Incorporating antioxidants into food packaging materials to control the oxidation of fatty components and pigments may contribute to the preservation of the quality of food products. ${ }^{42}$ The incorporation of AECs into cellulose matrix introduced a radical scavenging functionality in this biodegradable polymer. As shown in Fig. 9, cellulose film without AECs produced a small antioxidant response, which could be attributed to hydroxyl moieties along the cellulose chains. However, free

Table 2 Thickness, equilibrium moisture content, film solubility in water and water vapor permeability (WVP) of films

\begin{tabular}{|c|c|c|c|c|}
\hline Content of AECs & $\begin{array}{l}\text { Thickness } \\
(\mu \mathrm{m})\end{array}$ & $\begin{array}{l}\text { Equilibrium moisture } \\
\text { content }(\%)\end{array}$ & $\begin{array}{l}\text { Film solubility } \\
\text { in water }(\%)\end{array}$ & $\begin{array}{l}\mathrm{WVP} \times 10^{11} \\
\left(\mathrm{~g} \mathrm{~m}^{-1} \mathrm{~s}^{-1} \mathrm{~Pa}^{-1}\right)\end{array}$ \\
\hline 0 & $52.39 \pm 3.25$ & $3.81 \pm 0.64$ & $2.22 \pm 0.32$ & $6.25 \pm 0.33$ \\
\hline $1 \%$ & $51.61 \pm 1.87$ & $4.75 \pm 0.53$ & $4.35 \pm 0.24$ & $7.32 \pm 0.20$ \\
\hline $3 \%$ & $51.04 \pm 2.01$ & $6.98 \pm 0.92$ & $5.91 \pm 0.31$ & $7.51 \pm 0.35$ \\
\hline $5 \%$ & $50.46 \pm 0.79$ & $8.23 \pm 0.89$ & $7.07 \pm 0.25$ & $7.67 \pm 0.74$ \\
\hline
\end{tabular}




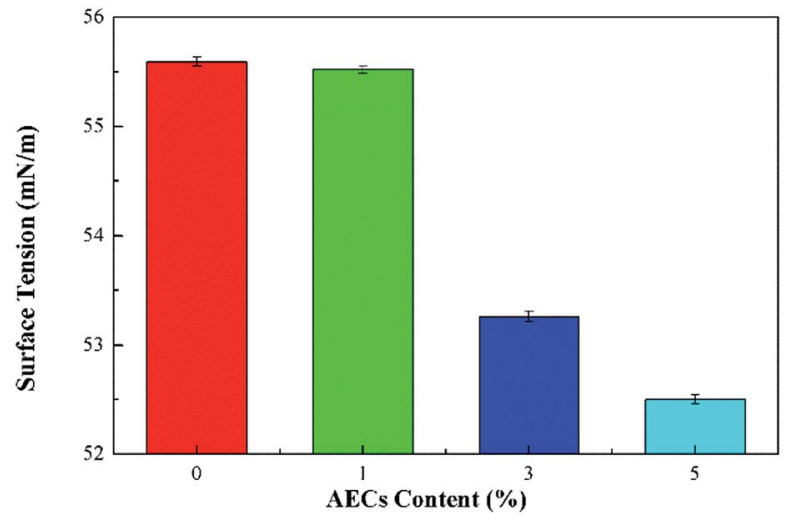

Fig. 8 Surface tension of the films with various amounts of AECs.

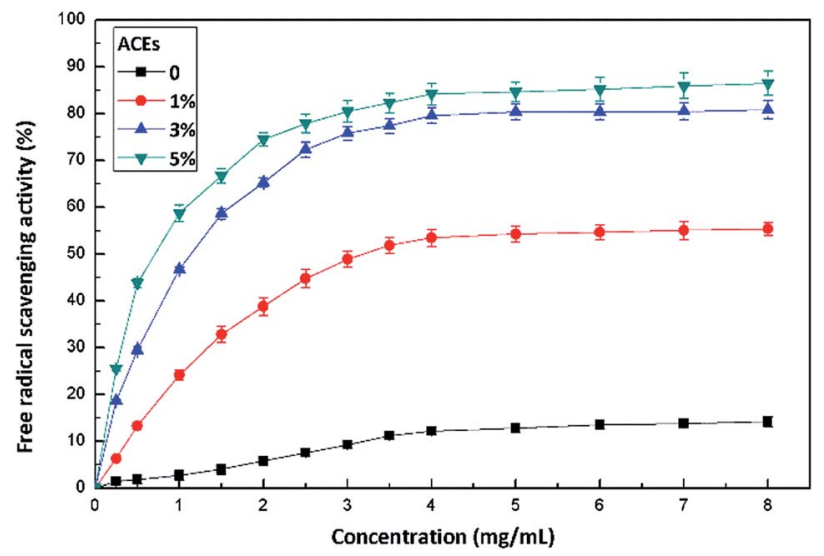

Fig. 9 DPPH radical scavenging activity of the composite films with various contents of AECs.

radical scavenging activity by incorporating AECs at a concentration as low as $1 \%$ in cellulose was clearly seen. The scavenging activity was concentration dependent with a minimum of $55.4 \% \pm 1.3 \%$ for $1 \%$ AECs to $86.5 \% \pm 2.7 \%$ for $5 \%$ AECs. The increased free radical scavenging activity of AEC/cellulose composite films was in direct relation to the higher $\mathrm{NH}_{2} \%$ of incorporated AECs, which was in accordance with previous reports demonstrating that higher $\mathrm{NH}_{2} \%$ resulted in better scavenging activity. ${ }^{\mathbf{4 3}, 44}$

\section{Conclusions}

This study reported the preparation of bioactive composite films from AECs (a novel chitosan derivative) and cellulose using an environmentally friendly casting method. Addition of various amounts of AECs affected the moisture, water vapor permeability, mechanical strength and antioxidant activity of the prepared composite films. Moreover, these composite films with good antioxidant activity have the potential to tailor physical and mechanical properties. Results from this study indicated that incorporation of AECs into the films can lead to possible applications in the food industry, considering the bioactivity and antioxidant activity of both the natural polymers.

\section{Acknowledgements}

This study was financially supported by the National Natural Science Foundation of China (no. 51473120).

\section{Notes and references}

1 X. Hua, K. Wang, R. Yang, J. Kang and J. Zhang, Food Hydrocolloids, 2015, 44, 122-128.

2 Z. A. Nur Hanani, Y. H. Roos and J. P. Kerry, Int. J. Biol. Macromol., 2014, 71, 94-102.

3 A. Linder, R. Bergman, A. Bodin and P. Gatenholm, Langmuir, 2003, 19, 5072-5077.

4 M. Atef, M. Rezaei and R. Behrooz, Int. J. Biol. Macromol., 2014, 70, 537-544.

5 G. Seyhun, Y. Ahmet and A. Sacidealsoy, J. Food Eng., 2009, 90, 453-462.

6 A. Safoura, K. Javad, N. Ali, H. Nasser, B. Tayebeh and A. Lionel, J. Appl. Polym. Sci., 2016, 133, 398-401.

7 C. Pastor, L. Sanchez-Gonzalez, A. Chiralt, M. Chafer and C. Gonzalez-Martinez, Food Hydrocolloids, 2013, 30, 272-280.

8 G. Davidov-Pardo and D. J. Mcclements, Trends Food Sci. Technol., 2014, 38, 88-103.

9 G. M. Raghavendra, T. Jayaramudu, K. Varaprasad, S. Ramesh and K. M. Raju, RSC Adv., 2013, 4, 3494-3501.

10 D. Fong, M. B. Ariganello, J. Girard-Lauziere and C. D. Hoemann, Acta Biomater., 2014, 12, 183-194.

11 A. M. El-Shafei, M. M. G. Fouda, D. Knittel and E. Schollmeyer, J. Appl. Polym. Sci., 2008, 110, 1289-1296.

12 H. Tamura, T. Furuike, S. V. Nair and R. Jayakumar, Carbohydr. Polym., 2011, 84, 820-824.

13 S. I. Hong, H. L. Jin, H. J. Bae, Y. K. Song, H. S. Lee and J. H. Choi, J. Appl. Polym. Sci., 2011, 119, 2742-2749.

14 L. Casettari, D. Vllasaliu, E. Castagnino, S. Stolnik, S. Howdle and L. Illum, Prog. Polym. Sci., 2012, 37, 659-685.

15 L. Zavaleta-Avejar, E. Bosquez-Molina, M. Gimeno, J. P. Perez-Orozco and K. Shirai, Food Hydrocolloids, 2014, 39, 113-119.

16 G. Q. Ying, W. Y. Xiong and H. Wang, Carbohydr. Polym., 2011, 83, 1787-1796.

17 W. Zhu and Z. Zhang, Int. J. Biol. Macromol., 2014, 70, 150155.

18 M. Pereda, G. Amica and N. E. Marcovich, Carbohydr. Polym., 2012, 87, 1318-1325.

19 A. P. Martínez, Carbohydr. Polym., 2010, 82, 305-315.

20 M. Srivastava, P. Rai, J. Singh and J. Singh, RSC Adv., 2014, 46, 30592-30597.

21 H. P. Fink, J. Ganster and A. Lehmann, Cellulose, 2014, 21, 31-51.

22 J. G. Huddleston, A. E. Visser, W. M. Reichert, H. D. Willauer, G. A. Broker and R. D. Rogers, Green Chem., 2001, 3, 156-164.

23 C. Yue, D. Fang, L. Liu and T. F. Yi, J. Mol. Liq., 2011, 163, 99121.

24 R. D. Rogers and K. R. Seddon, Science, 2003, 302, 792-793.

25 Y. Fukaya, K. Hayashi, M. Wada and H. Ohno, Green Chem., 2007, 10, 44-46. 
26 T. Q. Yuan, S. N. Sun, F. Xu and R. C. Sun, J. Agric. Food Chem., 2011, 59, 10604-10614.

27 A. Takaragi, M. Minoda, T. Miyamoto, Q. L. Hai and N. Z. Li, Cellulose., 1999, 6, 93-102.

28 Z. Li, X. F. Liu, X. P. Zhuang, Y. Guan and K. Yao, J. Appl. Polym. Sci., 2002, 84, 2049-2059.

29 W. Dhaeze, C. Verplancke, V. Mironov and M. Holsters, Plasmid, 2002, 47, 88-93.

30 X. He and M. B. Hagg, Chem. Eng. J., 2012, 215, 440-448.

31 M. A. GarciA, A. Pinotti, M. N. Martino and N. E. Zaritzky, Carbohydr. Polym., 2004, 56, 339-345.

32 C. Andreuccetti, R. A. Carvalho, T. Galicia-Garcia, F. Martinez-Bustos and C. R. F. Grosso, J. Food Eng., 2011, 103, 129-136.

33 Y. C. Chen, S. H. Yu, G. J. Tsai, D. W. Tang, F. L. Mi and Y. P. Peng, J. Agric. Food Chem., 2010, 58, 6728-6734.

34 D. W. Tang, S. H. Yu, Y. C. Ho, B. Q. Huang, G. J. Tsai and H. Y. Hsieh, Food Hydrocolloids, 2013, 30, 33-41.

35 A. K. Giri, R. Patel and S. Mandal, Chem. Eng. J., 2012, 185, 71-81.
36 X. Li, D. Yang, Y. Jiang and H. Fu, Green Chem., 2010, 12, 224-225.

37 R. E. Hunter and N. E. Dweltz, J. Appl. Polym. Sci., 1979, 23, 249-259.

38 S. Raymond, A. Kvick and H. Chanzy, Macromolecules, 2002, 28, 8422-8425.

39 J. P. D. Mesquita, C. L. Donnici and F. V. Pereira, Biomacromolecules, 2010, 11, 473-480.

40 M. Krumova, D. Lopez, R. Benavente, C. Mijangos and J. M. Perena, Polymer, 2000, 41, 9265-9272.

41 P. Hernandez-Munoz, R. Gavara and R. J. J. Hernandez, J. Membr. Sci., 1999, 154, 195-204.

42 N. Tammineni, B. Rasco, J. Powers, C. Nindo and G. J. Unlu, J. Agric. Food Chem., 2014, 2, 93-102.

43 W. Xie, P. Xu and Q. Liu, Bioorg. Med. Chem. Lett., 2001, 11, 1699-1701.

44 M. S. Rao, R. Chander and A. Sharma, J. Food Sci., 2005, 70, 325-331. 